DOI: https://doi.org/10.33330/jurteksi.v5i1.301

Available online at http://jurnal.stmikroyal.ac.id/index.php/jurteksi

\title{
ANALISIS PENGARUH PEMASANGAN SEPULUH KAPASITOR KERAMIK 6.8 NF/ 100V TERHADAP PENGIRIMAN DAYA TANPA KABEL DENGAN RANGKAIAN ROYER
}

\author{
${ }^{1}$ Ricki Ananda, ${ }^{2}$ Muhammad Amin \\ ${ }^{1,2}$ STMIK Royal Kisaran \\ email ${ }^{1}$ rickianandainterface@ gmail.com ${ }^{2}$ stmikroyal13@gmail.com
}

\begin{abstract}
Abstrack: Wireless usage is no longer only able to send data or files, power delivery or power transfer can be applied using wireless networking technology system or also called wireless energy transfer. Research purposes, to make prototype power wireless transfer by using royer oscilator circuit, and turning the load to the maximum with the minimum possible input. Using the $9.8 \mathrm{~V}$ input from Trafo 5A and changing the capacitor value of $6.8 \mathrm{nf} / 100 \mathrm{v} \times 10 \mathrm{C}$ on the transmitter (coil transmitter bigger than coil receiver). Installation of each capacitor with a distance of $7 \mathrm{~cm}$, give effect to maximal value increase, with Voltage 14.2 V, current $0.02 \mathrm{~A}$, power $0.284 \mathrm{~W}$ and Decrease Freq 610.5 $\mathrm{KHz}$. As for the distance of $12 \mathrm{~cm}$ also get a maximum value of $11.8 \mathrm{~V}$ voltage, current $0.02 \mathrm{~A}$, and a decrease in Frequency $614 \mathrm{Khz}$. The greatest efficiency at both distances is obtained, $\eta_{7 \mathrm{~cm}}=96,5$ and $\eta_{12 \mathrm{~cm}}=80,2$. To turn the load to the maximum (7 lamps used $7 \mathrm{~W}$ lamps with a total load $28 \mathrm{~W}$ ), PWT connected to USB $5 \mathrm{~V}$, and connected to battery and booster converter circuit so the distance is $12 \mathrm{~cm}$, obtained input voltage 2.2 and output voltage $47.8 \mathrm{~V}$, with output power of $1.43 \mathrm{~W}$, current $0.03 \mathrm{~A}$, and percentage increase of 2072 voltage. Installation of capacitors affects the voltage values, current, distance and power on the receiver. To light a large load, used a series of booster converter to power $28 \mathrm{~W}$ load, with $3.7 \mathrm{~V}$ input on battery packed on USB 5V, type TP4056.
\end{abstract}

Keyword : Royer Oscillator circuit, Power wireless transfer, Booster converter circuit

Abstrak: Penggunaan Wireless saat ini tidak lagi hanya bisa mengirim data atau file, pengiriman daya atau perpindahan daya bisa diterapkan menggunakan sistem teknologi jaringan nirkabel atau disebut juga wireless energy transfer. Tujuan penelitian, untuk membuat prototype power wireless transfer dengan menggunakan rangkaian royer oscilator, dan menyalakan beban secara maksimal dengan input seminimal mungkin. Dengan menggunakan input $9.8 \mathrm{~V}$ dari Trafo $5 \mathrm{~A}$ dan perubahaan nilai kapasitor $6,8 \mathrm{nf} /$ 100v x10 C pada bagian transmitter (coil transmitter lebih besar dari coil receiver). Pemasangan tiap-tiap kapasitor dengan jarak $7 \mathrm{~cm}$, memberi dampak peningkatan nilai maksimal, dengan Tegangan 14.2 V, arus $0.02 \mathrm{~A}$, daya $0.284 \mathrm{~W}$ dan Penurunan Freq $610.5 \mathrm{KHz}$. Sedangkan untuk jarak $12 \mathrm{~cm}$ juga mendapatkan nilai maksimal tegangan $11.8 \mathrm{~V}$, arus $0.02 \mathrm{~A}$, dan penurunan Frequensi $614 \mathrm{Khz}$. Efisiensi terbesar pada kedua jarak tersebut didapat, $\eta_{7 \mathrm{~cm}}=96,5$ dan $\eta_{12 \mathrm{~cm}}=80,2$. Untuk menyalakan beban secara maksimal (beban digunakan lampu $7 \mathrm{~W}$ sebanyak 4 lampu dengan total beban $28 \mathrm{~W}$ ), PWT dihubungkan ke USB $5 \mathrm{~V}$, dan terhubung ke baterai dan rangkaian booster converter, sehingga jarak $12 \mathrm{~cm}$, didapat input tegangan 2.2 dan keluaran tegangan 47.8 $\mathrm{V}$, dengan daya keluaran $1.43 \mathrm{~W}$, arus $0.03 \mathrm{~A}$, dan Persentasi kenaikan tegangan 2072. Pemasangan kapasitor mempengaruhi nilai tegangan, arus,jarak dan daya pada receiver. Untuk menyalakan beban yang besar, digunakan rangkaian booster converter untuk 
DOI: https://doi.org/10.33330/jurteksi.v5i1.301

Available online at http://jurnal.stmikroyal.ac.id/index.php/jurteksi

menyalakan beban $28 \mathrm{~W}$, dengan input $3.7 \mathrm{~V}$ pada baterai yang dicas pada USB $5 \mathrm{~V}$, jenis TP-4056.

Kata Kunci : Rangkaian Royyer Oscillator, Power wireless transfer , Rangkain Booster

\section{PENDAHULUAN}

Jaringan nirkabel atau umum disebut jaringan wireless merupakan tekhnologi yang umum digunakan untuk mengirim file atau data pada tiap tiap komputer. Pengiriman file tergantung dari jarak. Pada jarak 0$5 \mathrm{~cm}$ (Infrared/IR), menggunakan photo dioda. Jarak 0-5m menggunakan bluetooth (HC-05) dan jarak antara 0-100 meter menggunakan WAN (Work Area Network), biasanya mengirim file atau data dari tiap kota kekota lainnya.

Perkembangan teknologi tanpa kabel (Wireless) bisa digunakan untuk mengirim daya atau energi, hal ini dikenal dengan istilah Wireless Energy Transfer(WPT). Dasar prinsip kerja dari WPT dengan memanfaatkan dua self resonator yang memiliki frekuensi resonansi yang sama dapat mentransfer energi secar efisien dengan jarak yang tertentu [1].

Banyak penelitian yang telah membahas tentang ini, diantaranya Niko Tesla, 1893. Dengan membangun menara Wardenclyffe di Shoreham, niko tesla mampu menyalakan lampu pijar, dengan jarak pengiriman 27 meter [2]. Syed khalid Rakhman "dkk" mendapat hasil penelitian yang mereka lakukan dimana pada jarak $12 \mathrm{~cm}$ dan $15 \mathrm{~cm}$, tegangan pada receiver 0.108 , arus $0.00143 \mathrm{~A}$, daya $154.44 \mu \mathrm{W}$ dan pada receiver dua mendapat data tegangan
$0.0253 \mathrm{~V}$, arus $0.00199 \mathrm{~A}$, daya $50.347 \mu \mathrm{W}$. Dengan efisiensi pada receiver satu 21.54366 dan efisiensi pada receiver dua 3.374351 [3]. Penelitian yang dilakukan oleh Fareq dan kawan-kawan, tahun 2014 yang berjudul Low wireless power transfer using inductive coupling for mobil phone menyimpulkan bahwa hasil dari percobaan yang telah dilakukan, transfer daya nirkabel tidak banyak terpengaruh oleh bahan pelindung berupa tangan, buku maupun jenis pelastik [4].

Penelitian yang akan dilakukan memfokuskan perancangan rangkaian transmitter dengan menggunakan royer oscilator, dan apakah ada pengaruh terhadap tegangan, arus daya dan efisiensi pada rangkaian receiver pada saat nilai kapasitor ditambahi pada rangkaian royyer oscillator.

\section{Magnet}

Suatu penghantar bisa menjadi medan magnet jika kawat tersebut dialiri oleh arus dan penghantar tersebut berosilasi dengan waktu. Kuat arah, dan luas medan magnet sering divisualisasi seperti Gambar dibawah ini:

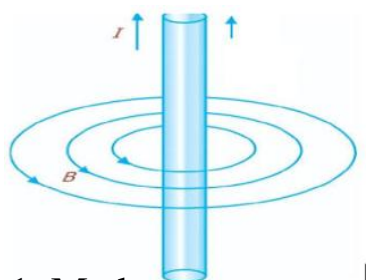

Gambar 1. Medan magnet yang dihasilkan kawat berarus 
DOI: https://doi.org/10.33330/jurteksi.v5i1.301

Available online at http:/jurnal.stmikroyal.ac.id/index.php/jurteksi

Pada saat arus mengalir pada suatu kawat penghantar, akan menimbulkan medan magnet (B) yang membungkus disekitar kawat. Ketika arus berbalik arah, medan magnet juga berbalik arah. Seperti ditunjukan pada persamaan 2.1 [5].

$$
\boldsymbol{B}=\frac{\mu_{0} \mathrm{I}}{2 \pi \mathrm{R}} \mathbf{a}_{\mathrm{r}}
$$

Pada Gambar 2. menjelaskan bahwa pada saat arus mengalir pada suatu coil penghantar akan menimbulkan medan magnet (B) garis medan magnet tercipta pada saat arus mengalir melalui coil atau konduktor. pada saat arus berbalik arah, medan magnet juga berbalik arah.

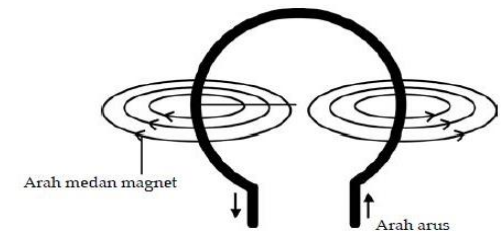

Gambar 2. Proses Medan magnet pada satu kumparan

\section{Induksi Magnet}

Transformator

merupakan

peralatan listrik yang mampu mentransfer arus untuk menaikan atau menurunkan suatu tegangan. Pada Gambar 3. Menjelaskan bahwa trafo memiliki dua bagian berupa primer dan skunder. Pada saat trafo dialiri tegangan, maka akan terjadi induksi bersama antara lilitan primer dengan skunder.

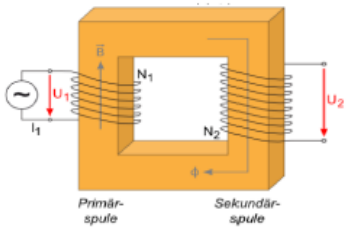

Gambar 3. Kontruksi Trafo
Pada kumparan primer, terdiri atas N1 lilitan dan dihubungkan dengan sumber tegangan. Sedangkan kumparan skunder, terdiri atas N2 tanpa dihubungkan dengan sumber tegangan dari luar. Akibat perubahan arus yang dihasilkan sumber pada kumparan primer, fluks magnet yang melalui kumparan skunder berubah terhadap waktu, maka timbul GGL induksi pada kumparan skunder. hubungan tersebut dinyatakan dalam Persamaan 2.2 [5].

$$
\varepsilon=-N \frac{d \Phi_{B}}{d t}=-\frac{d N \Phi_{B}}{d t}
$$

\section{Resonansi Kopling Magnetik}

Kopling magnetik terjadi ketika dua benda bertukar energi melalui medan magnet yang berosilasi. Kopling resonan terjadi ketika frekuensi alami dari dua objek yang kira-kira sama.

Pada Gambar 4. ditunjukkan penggunaan rangkaian power wireless transfer dengan menggunakan mosfet type TIP 35C. Dilihat dari prinsip kerjanya, TIP 35C, akan menguatkan arus yang akan dialiri ke lilitan coil transmitter [6].

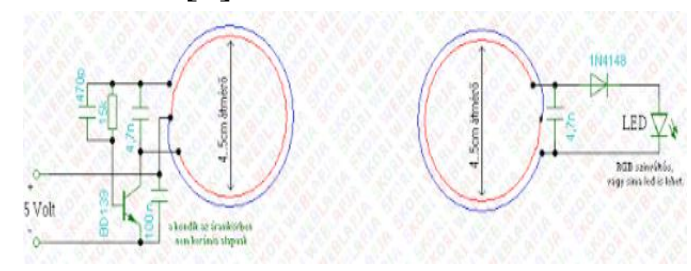

Gambar 4. Rangkaian Power Wireless

\subsection{Royyer Oscilator}

Royer oscillator merupakan rangkaian osilasi yang berfungsi untuk menciptakan daya dan frekuensi yang besar, sehingga tidak membutuhkan rangkaian penguat 
DOI: https://doi.org/10.33330/jurteksi.v5i1.301

Available online at http://jurnal.stmikroyal.ac.id/index.php/jurteksi

Radio frequency (RF).

Pada rangkaian royer oscilator terdapat komponen LC, dimana perubahan yang dilakukan oleh LC membuat frekuensi.

Penggunaaan dua choke, dua semikonduktor (MOSFET), kapasitor beresonansi, dikopel menyilang umpan balik melali dua dioda zener. Sehingga arus mengalir melali dua sisi choke atau kumparan dan menguras mosfet. Pada saat yang sama tegangan muncul di kedua gerbang dan mulai mengubah mosfet menjadi ON, sehingga mosfet yang satunya akan menyala.

\section{Rangkaian Booster converter}

Pada sistem rangkaian yang menggunakan tenaga baterai sebagai input, sering menserikan sel baterai untuk mendapatkan tegangan lebih tinggi. Terkadang penumpukan sel tidak bisa dilakukan, dikarenkan ruang yang tidak mencukupi. Untuk meningkatkan tegangan keluaran bisa menggunakan converter dan mengurangi jumlah sel [7].

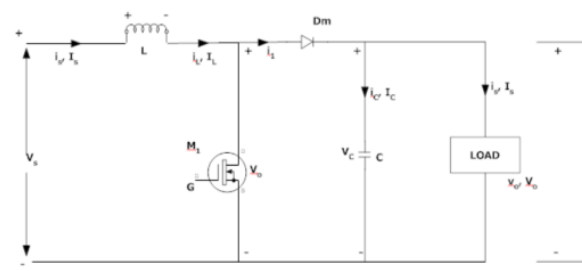

Gambar 5. Rangkaian diagram booster converter.

Salah satu aplikasi konsep diatas adalah rangkaian yang disebut Joulethief. Sirkuit Joule-thief dikenal sebagai rangkaian transistor pemblokiran sederhana yang bekerja sebagai pencuri energi yang bisa menghasilkan energi listrik besar dengan sumber energi sangat kecil. Rangkaian Joule-thief memiliki efisiensi tinggi, akselerasi handal dan respon dinamis yang sangat cepat [8].

\section{METODE}

Penelitian yang dilakukan bertujuan untuk menganalisis penggunaan rangkaian royyer oscilator sebagai rangkaian transmitter pada power wireless transfer, sehingga didapati apakah ada pengaruh yang signifikan penggunaan royer oscilator jika dibandingkan dengan rangkaian lainnya.

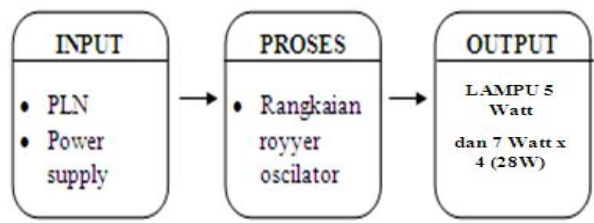

Gambar 6. Data Flow Diagram Power Wireless Transfer

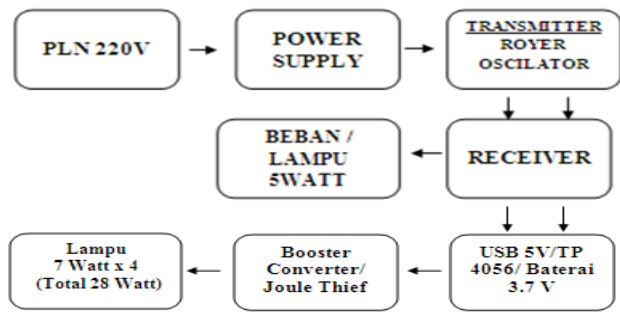

Gambar 7. Blok diagram transfer daya dengan rangkaian royyer oscilator

\section{Power Supply}

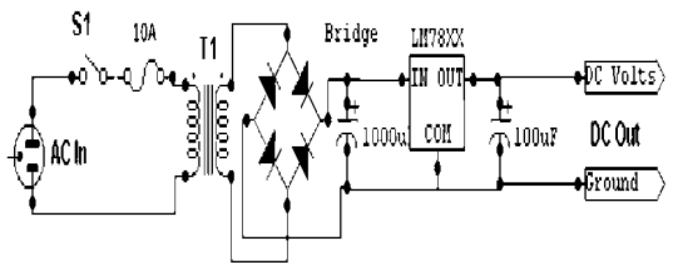

Gambar 8. Rangkaian Scematik Power Supply 
JURTEKSI (Jurnal Teknologi dan Sistem Informasi)

Vol. V No. 1, Des 2018, hlm. 71 - 80

DOI: https://doi.org/10.33330/jurteksi.v5i1.301

Available online at http://jurnal.stmikroyal.ac.id/index.php/jurteksi

\section{Rangkaian Royyer Oscilator (Transmitter)}

Tabel 1. Komponen Rangkaian Transmitter

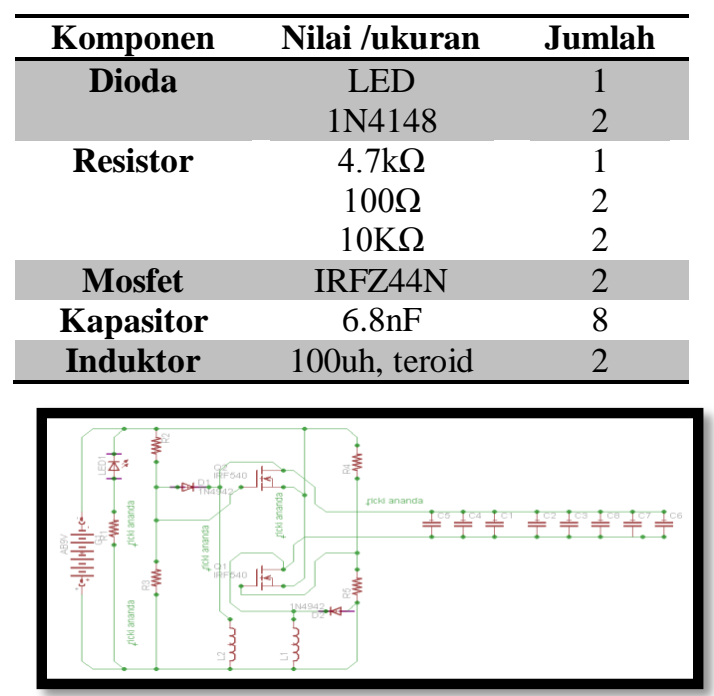

Gambar 9. Rangkaian Skematik Royyer Oscilator

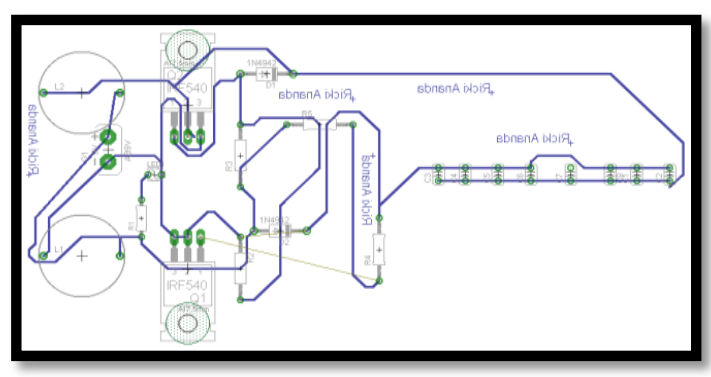

Gambar 10. Rangkaian Board Royyer Oscilator

\subsection{Rangkaian Booster Converter}

Tabel 2. Komponen Rangkaian Booster Converter

\begin{tabular}{ccc}
\hline Komponen & Nilai /ukuran & Jumlah \\
\hline Trafo & Feedback & 1 \\
Mosfet & FZR4552 & 1 \\
Resistor & 100 Ohm & 1 \\
Capasitor & $100 u f / 50 V$ & 1 \\
USB 5V & TP 4056 & 1 \\
Baterai & $3.7 \mathrm{~V}$ & 1 \\
\hline
\end{tabular}

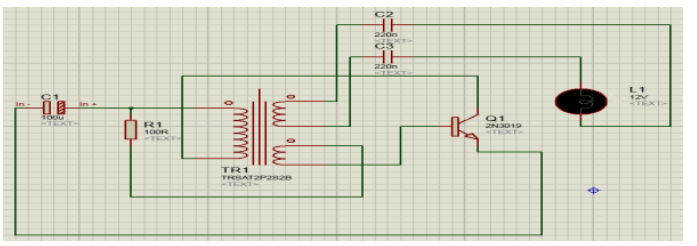

Gambar 11. Rangkaian Skematik Booster Converter

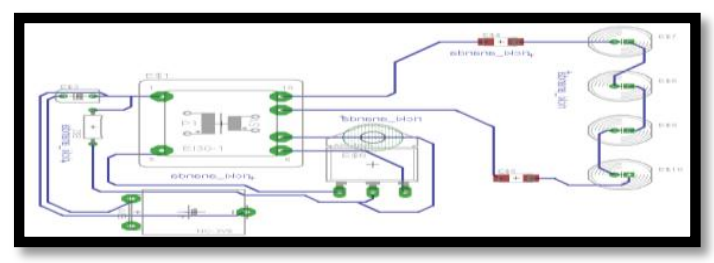

Gambar 12. Rangkaian Board Royyer Oscilator

\section{HASIL DAN PEMBAHASAN}

\section{Kalibrasi Awal Oscilloscope dan Ammeter}

Hasil awal kalibrasi oscilloscope dan multitester ditunjukan pada tabel 3.

Tabel 3. Hasil awal kalibrasi oscilloskop OWON, type PDS 5022T

\begin{tabular}{llll}
\hline Freq & $\mathbf{1 ~ M H z}$ & Vamp & $\mathbf{4 . 7 ~ V}$ \\
\hline Vpk-pk & $5.040 \mathrm{~V}$ & Overshoot & $3.4 \%$ \\
Periode (T) & $1.000 \mathrm{~ms}$ & preshoot & $3.4 \%$ \\
Cyc RMS & $3.4 \mathrm{~V}$ & Rise Time & $<1.000 \mathrm{us}$ \\
Vmax & $4.9 \mathrm{~V}$ & Fall time & $<1.000 \mathrm{us}$ \\
Vmin & $-80 . \mathrm{V}$ & +duty & $49.9 \%$ \\
Vtop & $4.8 \mathrm{~V}$ & -duty & $50.1 \%$ \\
Vbase & $80 \mathrm{mV}$ & Mean & $2.43 \mathrm{~V}$ \\
\hline
\end{tabular}

Hasil awal kalibrasi bertujuan untuk settingan oscilloscop pada posisi standart pabrikan, sehingga didapat hasil frekuensi dari kalibrasi $1 \mathrm{Khz}$, dan tegangan puncak kepuncak 5V. Sementara hasil pengukuran dari ammeter didapat tegangan 4,9 Volt.

Pengujian Pemasangan Kapasitor Jenis kapasitor yang digunakan jenis keramik dengan nilai $6,8 n f$ 
JURTEKSI (Jurnal Teknologi dan Sistem Informasi)

Vol. V No. 1, Des 2018, hlm. 71 - 80

DOI: https://doi.org/10.33330/jurteksi.v5i1.301

Available online at http://jurnal.stmikroyal.ac.id/index.php/jurteksi

\section{$/ 100 \mathrm{~V}$}

Pemasangan Pada Transmitter (TX)

Pemasangan kapasitor pada rangkaian transmitter mempengaruhi nilai keluaran arus yang akan
ISSN 2407-1811 (Print)

ISSN 2550-0201 (Online)

Tabel 4. Perbandingan Hasil penggunaan jumlah kapasitor pada Transmitter

\begin{tabular}{ccccccc}
\hline Kapasitor (C) & $\mathrm{V}_{\text {in }}$ & Arus (A) & Power (W) & Frequensi (F) & Vpk-pk & Periode (nS) \\
\hline $\mathbf{0}$ & 9,8 & 0 & 0 & $5,2 \mathrm{MHz}$ & $27,8 \mathrm{~V}$ & $57,1 \mathrm{nS}$ \\
$\mathbf{2}$ & 9,8 & 0,02 & 0,196 & $1,7 \mathrm{MHz}$ & $24,8 \mathrm{~V}$ & $63,2 \mathrm{nS}$ \\
$\mathbf{4}$ & 9,8 & 0,02 & 0,196 & $923 \mathrm{KHz}$ & $18,8 \mathrm{~V}$ & $71,9 \mathrm{nS}$ \\
$\mathbf{6}$ & 9,8 & 0,03 & 0,294 & $833 \mathrm{KHz}$ & $17,8 \mathrm{~V}$ & $72,2 \mathrm{nS}$ \\
$\mathbf{8}$ & 9,8 & 0,03 & 0,294 & $660 \mathrm{KHz}$ & $17,2 \mathrm{~V}$ & $93,9 \mathrm{nS}$ \\
$\mathbf{1 0}$ & 9,8 & 0,03 & 0,294 & $522 \mathrm{KHz}$ & $16,6 \mathrm{~V}$ & $94,6 \mathrm{nS}$ \\
\hline
\end{tabular}

Pada gambar 13 menunjukan gelombang merah, merupakan bentuk gelombang pada rangkaian transmitter pada saat diberi 10 Capasitor, dan gelombang kuning, merupakan rangkaian dari receiver.

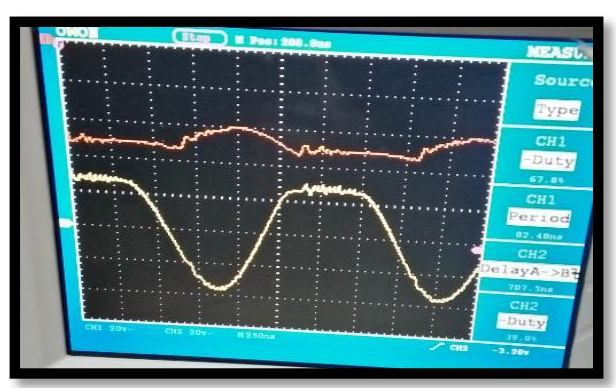

Gambar 13. Bentuk gelombang pada rangkaian transmitter dan receiver.

Pemasangan Pada Receiver (RX) jarak $7 \mathrm{~cm}$ dan $12 \mathrm{~cm}$. ditransferkan serta nilai frekuensi yang semakin mengecil, ditunjukan pada Tabel 4 
JURTEKSI (Jurnal Teknologi dan Sistem Informasi)

Vol. V No. 1, Des 2018, hlm. 71 - 80

DOI: https://doi.org/10.33330/jurteksi.v5i1.301

Available online at http://jurnal.stmikroyal.ac.id/index.php/jurteksi

Tabel 6. Pengaruh pemasangan

kapasitor pada rangkaian receiver dengan jarak $12 \mathrm{~cm}$

\begin{tabular}{cccccc}
\hline $\begin{array}{c}\text { Kapa } \\
\text { sitor } \\
(\mathrm{c})\end{array}$ & Vout & $\begin{array}{c}\text { Arus } \\
\left(\mathrm{I}_{\text {out }}\right)\end{array}$ & $\begin{array}{c}\text { Daya } \\
\left(\mathrm{P}_{\text {Out }}\right)\end{array}$ & $\begin{array}{c}\text { Frekue } \\
\text { nsi } \\
\left(\mathrm{F}_{\text {Out }}\right)\end{array}$ & $\begin{array}{c}\text { Vpk- } \\
\mathrm{pk}\end{array}$ \\
\hline $\mathbf{0}$ & 0 & 0 & 0 & $\begin{array}{c}7,70 \\
\mathrm{MHz}\end{array}$ & 20,8 \\
$\mathbf{2}$ & 0,9 & 0,01 & 0,009 & $\begin{array}{c}993,5 \\
\mathrm{Khz}\end{array}$ & 12,0 \\
$\mathbf{4}$ & 1,5 & 0,01 & 0,015 & $\begin{array}{c}981,0 \\
\mathrm{Khz}\end{array}$ & 13,6 \\
$\mathbf{6}$ & 5,7 & 0,02 & 0,114 & $\begin{array}{c}833,0 \\
\mathrm{Khz}\end{array}$ & 18,8 \\
$\mathbf{8}$ & 9,5 & 0,02 & 0,19 & $\begin{array}{c}708,2 \\
\mathrm{Khz}\end{array}$ & 56,0 \\
$\mathbf{1 0}$ & 11,8 & 0,02 & 0,236 & $\begin{array}{c}614,7 \\
\mathrm{Khz}\end{array}$ & 56,8 \\
\hline
\end{tabular}

Pada Gambar 14 Menunjukan pemasangan 10 kapasitor yang mengakibatkan lampu 5 Watt menyala terang pada rangkaian Receiver. Jarak antara coil transmitter dengan coil receiver berjarak $7 \mathrm{~cm}$.

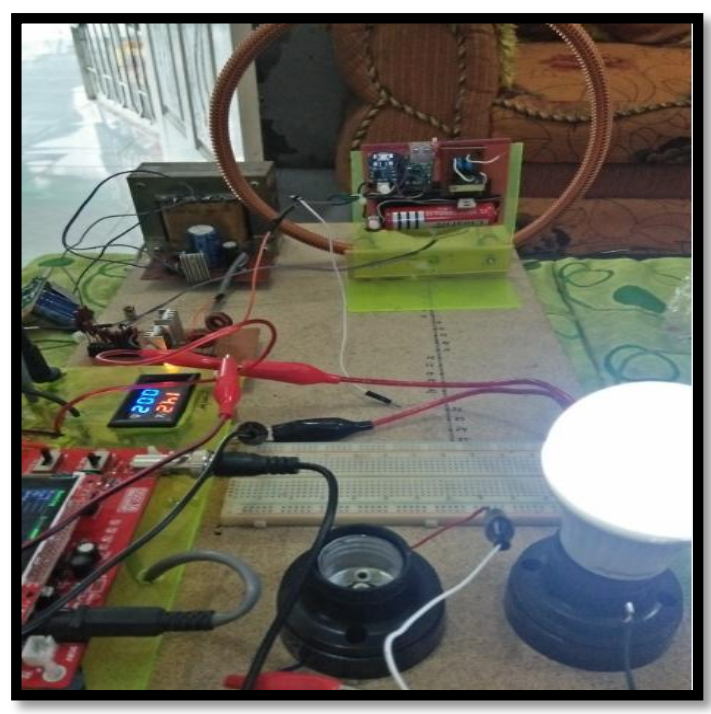

Gambar 14. Tampilan lampu pada saat diberi 10 Kapasitor

Pengukuran Output Booster konverter.

Pada tabel 7 ditunjukan hasil pengukuran dari 4 lampu 7watt, dengan total beban 28 wat.
ISSN 2407-1811 (Print)

ISSN 2550-0201 (Online)
Tabel 7. Hasil pengukuran output rangkaian Booster Converter

\begin{tabular}{cl}
\hline $\begin{array}{c}\text { Output Booster } \\
\text { Converter }\end{array}$ & \multicolumn{1}{c}{ Hasil } \\
\hline Frequensi & $19,94 \mathrm{MHz}$ \\
Period & $50,16 \mathrm{nS}$ \\
Vpk-pk & $8 \mathrm{~V}$ \\
Vmax & $43 \mathrm{~V}$ \\
Vmin & $-42 \mathrm{~V}$ \\
Vin & $3,7 \mathrm{~V}$ \\
Vout & $47,8 \mathrm{~V}$ \\
Iout & $0,03 \mathrm{~A}$ \\
Beban & $28 \mathrm{~W}$ \\
\hline
\end{tabular}

Pada Gambar 15 Menunjukan nyala lampu dari output rangkaian booster converter.

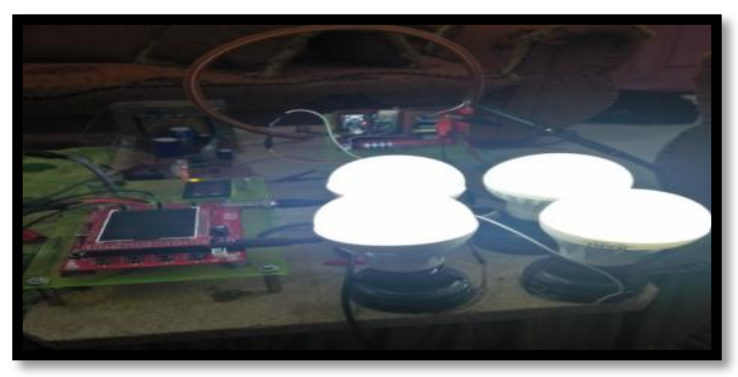

Gambar 15. Tampilan nyala led 28 $\mathrm{W}$, dengan input $3.7 \mathrm{~V}$

Perhitungan dan perbandingan efisiensi yang dihasilkan pada rangkaian TX dan $R X$

Tujuan dilakukan penghitungan efisiensi antara rangkaian transmitter dengan receiver, serta antara rangkaian receiver dengan ouput booster coonverter, bertujuan untuk mengetahui apakah prototype power wireless transfer termasuk dalam kategori efisien.

$$
\eta=\frac{P_{\text {out }}}{P_{\text {in }}} x 100 \%
$$

Berdasarkan daya masukan dari rangkaian transmitter pada Tabel 4.2, dan daya keluaran dari rangkaian 
JURTEKSI (Jurnal Teknologi dan Sistem Informasi)

Vol. V No. 1, Des 2018, hlm. 71 - 80

DOI: https://doi.org/10.33330/jurteksi.v5i1.301

Available online at http://jurnal.stmikroyal.ac.id/index.php/jurteksi

receiver pada jarak $7 \mathrm{~cm}$ Pada tabel 4.3 , dan $12 \mathrm{~cm}$ pada Tabel 4.4 didapat Efisiensi yang ditunjukan pada Tabel 4.6

Tabel 16 Efisiensi pada jarak $7 \mathrm{~cm}$ dan $12 \mathrm{~cm}$, menggunakan beban 5 Watt.

\section{Effisiensi}

\begin{tabular}{cc}
\hline Eff / 7cm & Eff/12 cm \\
\hline 0 & 0 \\
\hline 11,7 & 4,5 \\
\hline 55,1 & 7,6 \\
\hline 68,0 & 38, \\
\hline 73,4 & 64,6 \\
\hline 96,5 & 80,2 \\
\hline
\end{tabular}

Berdasarkan data Tabel 4.2, Tabel 4.3, dan Tabel 4.4 Bisa dibuat grafik perubahan nilai tegangan, arus, dan daya pada saat diberi kapasitor. Sehingga pengaruh perubahan nilai kapasitor juga mempengaruhi nilai efisiensi seperti data yang ditunjukan pada tabel 4.6

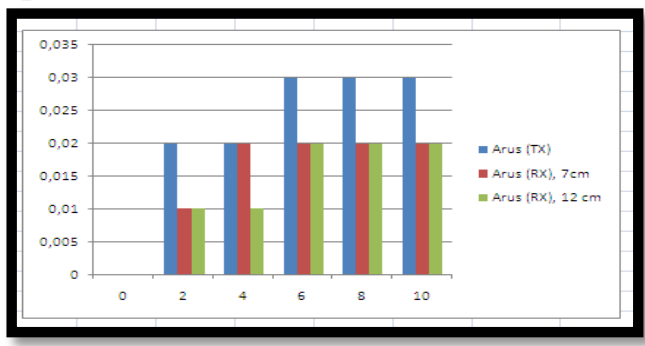

Gambar 16. Perbandingan Perubahan Arus saat nilai kapasitor diubah

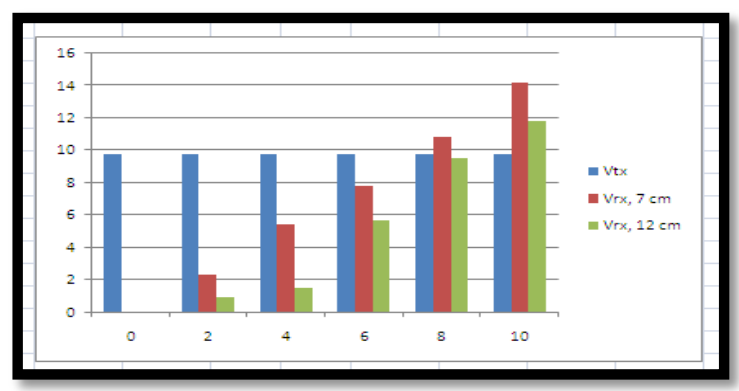

ISSN 2407-1811 (Print) ISSN 2550-0201 (Online)
Gambar 17. Perbandingan Perubahan

Tegangan saat nilai kapasitor diubah

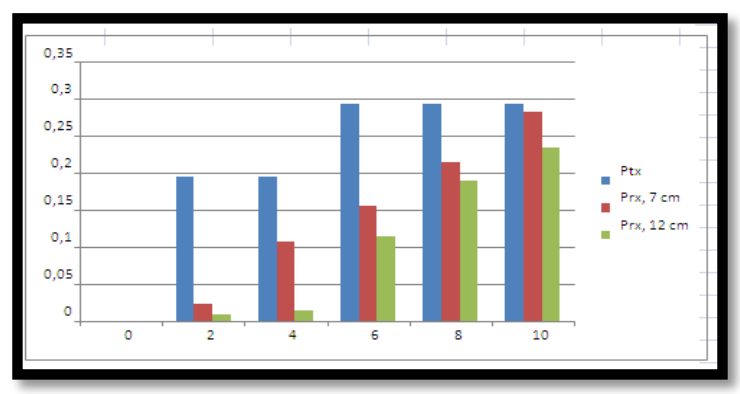

Gambar 18. Perbandingan perubahan Daya, saat nilai kapasitor diubah

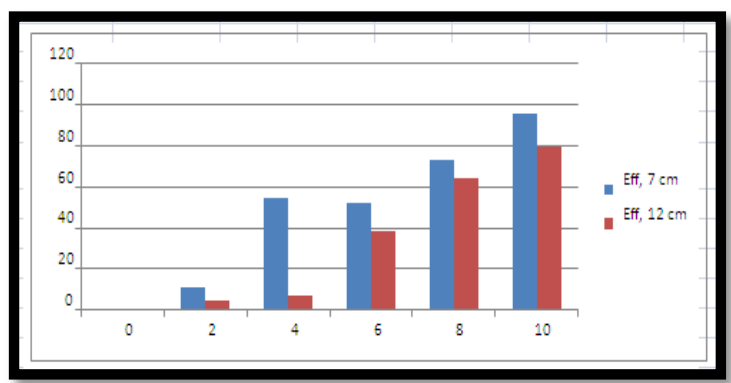

Gambar 19. Perbandingan perubahan Efisiensi, saat nilai kapasitor diubah

Persentasi kenaikan tegangan pada keluaran USB $5 \mathrm{~V}$, dengan Keluaran Booster Converter (Joule Thief)

Dengan membandingkan keluaran dari booster converter, dan input tegangan 3.7 Volt, yang dihubungkan ke booster converter untuk menyalakan lampu 7 watt sebanyak 4 buah, dengan total beban 28 watt. didapati hasil pada Tabel 4.7 
DOI: https://doi.org/10.33330/jurteksi.v5i1.301

Available online at http:/jurnal.stmikroyal.ac.id/index.php/jurteksi

Tabel 4.7 Persentasi kenaikan tegangan pada input dan output Booster converter

\begin{tabular}{cccccccc}
\hline Kapasitor (C) & $\begin{array}{c}\mathrm{V}_{\text {out/ }} \\
\text { USB }\end{array}$ & $\begin{array}{c}\text { Arus } \\
\left(\mathrm{I}_{\text {out }}\right)\end{array}$ & $\begin{array}{c}\text { Pout } \\
\text { USB }\end{array}$ & $\begin{array}{c}\text { Vout/ } \\
\text { Boost } \\
\text { er }\end{array}$ & $\begin{array}{c}\text { Iout/ } \\
\text { Boost } \\
\text { er }\end{array}$ & $\begin{array}{c}\text { Pout/ } \\
\text { Boost } \\
\text { er }\end{array}$ & $\begin{array}{c}\text { Persentasi } \\
\text { V (\%) }\end{array}$ \\
\hline $\mathbf{0}$ & 0 & 0 & 0 & 0 & 0 & 0 & 0 \\
$\mathbf{2}$ & 1,6 & 0,01 & 0,016 & 47,8 & 0,03 & 1,434 & 2887,5 \\
$\mathbf{4}$ & 1,6 & 0,01 & 0,016 & 47,8 & 0,03 & 1,434 & 2887,5 \\
$\mathbf{6}$ & 1,9 & 0,02 & 0,038 & 47,8 & 0,03 & 1,434 & 2415,7 \\
$\mathbf{8}$ & 2 & 0,02 & 0,04 & 47,8 & 0,03 & 1,434 & 2290 \\
$\mathbf{1 0}$ & 2,2 & 0,02 & 0,044 & 47,8 & 0,03 & 1,434 & 2072,7
\end{tabular}

\section{KESIMPULAN}

1. Dari data pengukuran yang telah dilakukan dengan menggunakan oscilloscope merk owon dan ammeter digital, pada rangkaian receiver pada jarak $7 \mathrm{~cm}$, didapat nilai arus maksimal $0.03 \mathrm{~A}$, Tegangan $14.8 \mathrm{~V}$, Daya 0.444. Dan untuk jarak $12 \mathrm{~cm}$, Arus maksimal 0.03 A, Tegangan 11.5 $\mathrm{V}$, daya $0,345 \mathrm{~W}$. Dengan input Transmitter 9,8 Volt dan arus 0,04 pada pemasangan 10 kapasitor.

2. Pemasangan jumlah kapasitor mempengaruhi nilai tegangan, arus dan frekuensi. Seperti pemasangan 2 kapasitor pada jarak $12 \mathrm{~cm}$ menghasilkan tegangan $0.9 \mathrm{~V}$, Arus 0.02A, Frekuensi 993.5 Khz, dan Pemasangan 10 Kapasitor menghasilkan tegangan $11.5 \mathrm{~V}$, Arus 0,03 A, dan Frekuensi 614,7 $\mathrm{Khz}$

3. Nilai daya maksimum pada rangkaian receiver dengan jarak 7 $\mathrm{cm}$, pada 10 kapasitor didapat daya $0.444 \mathrm{~W}$, dan efisiensi $113.3 \eta$. Sedangkan untuk jarak $12 \mathrm{~cm}$ pada 10 kapasitor didapat daya $0.345 \mathrm{~W}$, dan efisiensi $88.01 \eta$.
4. Output pada rangkaian bosster converter dengan beban $28 \mathrm{~W}$, menghasilkan tegangan $47.8 \mathrm{~V}$, arus $0.03 \mathrm{~A}$, daya $1,434 \mathrm{~W}$ dan efisiensi $2172.7 \eta$, dimana input pada rangkaian booster converter 3,7 $\mathrm{V}$ dari baterai.

\section{DAFTAR PUSTAKA}

[1] Sample P Alanson, Meyer A David. Smith R Joshua.Analysis, experimental results, and range adaption of magnetically coupled resonators for wireless power transfer. 2011.IEEE Vol.58, No. 2, February. 0278-0046/\$26.00.

[2] Valone F Thomas. Tesla's Wireless Energy For the 21st Century.2005. ExtraOrdinary Technology. Vol 1, issue 4.

[3] Rahman Syed Khalid, Ahmed Omar, Islam Saiful Md. Design and construction of wireless power transfer system using magnetic resonant coupling.2014. American journal of electromagnetic and applications.Vol 2. pp.11-15. doi : 10.11648

[4] M Fareq, and friends. Low wireless power transfer using inductive coupling for mobile phone charger. 2014. Journal of physics : confrence series 495 , 
DOI: https://doi.org/10.33330/jurteksi.v5i1.301

Available online at http://jurnal.stmikroyal.ac.id/index.php/jurteksi

doi:10.1088/1742-6596/495/1/

012019.

[5] Ngurah Tegar mahardika"dkk". Analisis perangkat transmisi untuk wireless energy transfer. 2014. JCONES.vol 3 no 1,. Hal 112-119.

[6] Muljono, Sunarto. Listrik Magnet-Penyelesaian soal soal. 2003. Andi. Yogyakarta

[7] Abdul Fathah. Design of a Boost Converter.June-2013.

Department of electrical engineering national institute of technology rourkela (ODISHAINDIA).Thesis- 769008.

[8] Mujadin Anwar dan Rahmatia Suci. Joule thief sebagai boost converter daya led menggunakan sel volta berbasis air laut. 2017. Jurnal Al-Azhar Indonesia Seri Sains dan Teknologi. Vol 4 Vo 2 September. 